\title{
Pandemic flu: current threat and development of a preparedness framework
}

\author{
K. Duncan \\ University of Toronto, Canada
}

\begin{abstract}
Experts agree that an influenza pandemic is inevitable and possibly imminent, since the highly pathogenic H5N1 influenza virus is mutating rapidly, is affecting new hosts, and is expanding its geographic range. Should an influenza strain emerge that spreads easily among humans, the World Health Organization predicts that 'all countries will be affected, widespread illness will occur, medical supplies will be inadequate, large numbers of deaths will occur, and economic and social disruption will be great'.

On January 19, 2006, UN Secretary General Kofi Annan warned of the possibility of human-to-human transmission of the Avian Influenza virus unless the international community pulled together in a massive effort to combat the virus. Michael Chertoff, Secretary of Homeland Security et al., appealed to the American business community on December 6, 2005, to prepare.

However, only $15 \%$ of large American companies had a bird-flu plan, according to a survey in March 2006, by human capital and financial management consultancy Watson Wyatt Worldwide. A June 2006, survey by The Conference Board of Canada showed that $80 \%$ of respondents' executives were concerned about the impact of a pandemic on their organization, but only $4 \%$ had developed a preparedness plan.

Today we have an unprecedented opportunity to prepare for a pandemic, and to reduce economic and social impacts, cases, hospitalizations and deaths. This paper will therefore develop a framework for pandemic preparedness for organizations, including employee health and welfare, ethical and legal issues, business continuity, and partnerships with government and civil society.

Keywords: pandemic influenza, pandemic preparedness, laws, regulations and ethical issues, business continuity.
\end{abstract}




\section{Introduction}

A pandemic of influenza 'is inevitable and possibly imminent' warns the World Health Organization (WHO) and influenza experts, who believe that we are closer to such than at any time since 1968, the year of the last pandemic (Webby and Webster [1]; Monto [2]; WHO [3]; and Duncan [4]).

Both groups are concerned that the widespread distribution of Avian Influenza virus, Influenza $\mathrm{A} / \mathrm{H} 5 \mathrm{~N} 1$, has the potential to ignite the next global epidemic for the following reasons. H5N1 is mutating rapidly, is affecting new hosts (such as cats and tigers), is rapidly expanding its geographic range, and is highly pathogenic and can cause severe disease in humans. In fact, since 2003, H5N1 has infected 274 people and killed 167 people (19/02/07) (WHO [5]).

Between February 2006, and April 2006, 32 countries, located in Africa, Asia, Europe, and the Middle East, reported their first cases in birds. This spread marked the fastest and most extensive geographical spread of any highly pathogenic influenza virus since the disease was first described in 1878. The virus has now affected some of the world's most densely populated and impoverished regions - areas poorly served by healthcare and surveillance systems (Duncan [6]).

On January 19, 2006, UN Secretary General Kofi Annan warned of the possibility of human-to-human transmission of the Avian Influenza virus unless the international community pulled together in a massive effort to combat the virus. Michael Chertoff, Secretary of Homeland Security, et al., appealed to the American business community on December 6, 2005: 'We are requesting that you, as a business leader, focus on the need for planning within your organization for the possibility of an influenza pandemic...your business should develop specific plans for the ways that you would protect your employees and maintain operations during a pandemic.'

However, only $15 \%$ of large American companies had a bird-flu plan, according to a survey in March 2006, by human capital and financial management consultancy Watson Wyatt Worldwide. A June 2006, survey by The Conference Board of Canada showed that $80 \%$ of respondents' executives were concerned about the impact of a pandemic on their organization, but only $4 \%$ had developed a preparedness plan.

Key issues for respondents were employee health and welfare (100\%), and operational continuity (96\%). Although respondents aimed to protect their organization from the effects of a global epidemic, they did not tackle 'the full range of challenges' they might face during a pandemic: for example, compensating individuals covering for absent employees, and responding to employees refusal to work in an unsafe environment. The most significant disadvantage was, however, the lack of coordination with the public sector; $94 \%$ of participating companies reported that they had not had discussions with any level of government officials (Duncan [7,8]).

Today we have an unprecedented opportunity to prepare for a pandemic, and to reduce economic and social impacts, cases, hospitalizations and deaths. We 
did not have this opportunity in 1918, nor did we have this chance in 2003 with the international outbreak of severe acute respiratory syndrome (SARS).

Therefore this paper will first discuss the current pandemic influenza threat, and the possible impacts of a worldwide event. The 1918 Spanish flu pandemic will be highlighted, as it sheds light on the destruction of human life and families, the chaos inflicted on the healthcare system, and the disruption to civil society, as well as providing a worse case scenario - these do happen, as shown by $9 / 11$, the Asian tsunami, and most recently, Hurricane Katrina.

This paper will second develop a framework for pandemic preparedness for organizations, including ethical and legal issues, business continuity, and partnerships with government and civil society.

\section{Pandemic: predicted impacts}

Should an influenza strain emerge that spreads easily among humans, the WHO predicts that 'all countries will be affected, widespread illness will occur, medical supplies will be inadequate, large numbers of deaths will occur, and economic and social disruption will be great'.

\subsection{All countries will be affected}

Once a contagious virus emerges, its global spread is considered inevitable. Countries might delay arrival of the virus (through measures such as border closures and travel restrictions), but will be unable to stop it. Countries and organizations must also prepare for two or more pandemic waves, either in the same year, or in successive years (WHO [9]).

The pandemics of the previous century circled the Earth in six to nine months, even though most international travel was by ship. In the autumn of 1918, the virus probably mutated, and hit three port cities thousands of miles apartFreetown, Sierra Leone, Brest, France, and Boston, United States (Crosby [10]; and Duncan [11]). Did the disease originate in one of the three ports, and travel instantaneously to the other two, or were these simultaneous mutations of the virus? To date, we have no answers to these important questions.

An examination of the years preceding 1918, however, suggests that mortality figures for bronchopneumonia increased in the United States between1914-'18, and 'purulent bronchitis' occurred in France (1916) and in Britain (1917) (Oxford et al., [12]).

The questions that beg to be asked are: did these early cases represent a seeding of the virus around the world, and are the current human cases of H5N1 similar to the possible cases of influenza between 1914-1918?

Given the speed and volume of international air travel today (in 2000, $60,000,000$ people visited the United States), the virus could spread more rapidly, possibly reaching all continents in less than three months (Duncan [4, 11]); today, we circumnavigate the Earth in 36 hours compared to 365 days in 1865. Within four months of the global SARS alert, more than 8000 people were affected in 30 countries across six continents; 900 people died (Duncan [4]). 


\subsection{Widespread illness will occur}

In the future, most people will have no immunity to a pandemic virus. As a result, infection and illness rates are expected to be higher than during seasonal epidemics of influenza; in Toronto, for example, 700,000 are expected to require medical care and 14,000 hospitalization. Few countries will have the facilities, staff, hospital beds, and equipment needed to cope with large numbers of people who suddenly fall ill (Duncan [4]; and WHO [9]).

In 1918, half the world's population fell sick to Spanish flu. The disease raged in Africa, Australia, Canada, Europe, New Zealand, the South Pacific, the United States - and even reached as far north as the Arctic archipelago of Svalbard, 1000 kilometres north of the Norwegian mainland.

In addition to Spanish flu, another worldwide scourge raged unabated: encephalitis lethargica--the disease depicted in the movie Awakenings (1990), based on the pioneering work of Dr. Oliver Sacks. During its reign of terror-from 1915 to its disappearance sometime between 1927 and 1930--, the disease claimed or ravaged the lives of 5,000,000 people worldwide (Duncan [11]). Regrettably, no causative agents were identified during the two pandemics; however, circumstantial evidence links Spanish flu and encephalitis lethargica or sleeping sickness (Duncan [6,11]).

Today $\mathrm{H} 5 \mathrm{~N} 1$ causes severe disease in animals and humans, with viral pneumonia and failure of many organs and the central nervous system (Liu et al., [13]; and WHO [3]). In 2004 a Vietnamese boy presented with severe diarrhea, followed by seizures, coma, and death. H5N1 was isolated from his cerebrospinal fluid and other specimens. The diagnosis, like his sister's, was acute encephalitis. 'These cases suggest that the spectrum of influenza H5N1 is wider than previously thought (de Jong et al., [14]).'

Recent research shows that H5N1 shares genetic similarities with the 1918 Spanish flu virus (Taubenberger et al., [15]). Moreover, H5N1 attacks multiple organs, including the central nervous system, of young healthy people, just as the Spanish flu virus did in 1918-19. Perhaps experts, preparing for an influenza pandemic, should therefore examine the possibility of a wider spectrum of H5N1, and a longer medical legacy (Duncan [7])? Consideration of these questions has implications for priority lists for antiviral drugs and vaccines, as well as organizational benefits, compensation packages and financial assistance.

\subsection{Medical services and supplies will be inadequate}

\subsubsection{Facilities and equipment}

Today the connection between emergency management and the public's health has never been more important. All hospitals should be prepared to meet the surge in demand for healthcare during an influenza pandemic. Hospitals should also participate in regional planning for the medical care of flu patients, since hospitals, individually and jointly, must be able to provide care for flu victims, while maintaining other essential medical services, during and after a pandemic. In addition, every hospital should stockpile, or assure access to a stockpile of, personal protective equipment for a sustained time period-perhaps eight weeks (Toner et al., [16]). 
In 1918, departments of health scrambled to co-ordinate medical institutions. As people fell ill by the thousands, more and more buildings were pressed into service as hospitals; in fact, even world-famous Sing-Sing Prison did time as a hospital (Duncan [11]).

\subsubsection{Staff and volunteers}

If a pandemic occurs, it will be imperative to determine the number of available healthcare workers, to triage, to determine patient flows and to identify suitable organizations to train volunteers for healthcare roles (Duncan [17]).

Each community must be prepared. This includes: developing demographic profiles for communities, including special needs populations and language minorities; developing containment measures (e.g. cancelling public transportation, closing schools and other public venues); and maintaining a current register of all active and once-active healthcare personnel available for emergency services (PandemicFlu.gov [18]).

\subsubsection{Medical supplies}

Today, the WHO has asked that each country develop county preparedness plans and stockpile drugs. Antiviral agents will be the principal medical intervention for reducing morbidity and mortality should a pandemic occur. In October 2005 , the Canadian national antiviral stockpile was comprised of 16 million doses of oseltamivir (Tamiflu), although some provinces and territories might have purchased additional stores. The supply fell far short of one dose for each Canadian, and in May 2006, the Canadian government announced that 55 million doses would be available for the population (CTV [19]).

A critical problem remains; that is, the drug needs to be administered shortly after the onset of symptoms, yet cases tend to be detected late in the course of illness (Duncan [6]). Therefore, there is tremendous need for suitable diagnostic tests and effective disease-reporting and drug-delivery systems to ensure that sick individuals receive treatment within 24 hours (for best results from the drug). There is also need for new antiviral agents for flexibility in developing prophylaxis/treatment.

In addition to stockpiling drugs, governments should also make the public aware of the means by which individual citizens can lessen the impacts on their families. For example, families might have medicines, non-prescription drugs, and other health supplies (e.g. fluids with electrolytes, pain relievers, and prescribed medical supplies, such as glucose monitoring equipment) on hand (PandemicFlu.gov [20,21]).

\subsubsection{Preventive measures}

Today, supplies of vaccines and antiviral drugs - the two most important medical interventions for reducing illness and deaths during a pandemic - will be inadequate in all countries at the start of a pandemic and for many months thereafter.

The greatest challenge is the six to twelve months needed to produce enough vaccine to protect citizens. Previous pandemics swept the Earth in six to nine months despite the fact that most international travel was by ship - unlike the 
rapid travel of today (Duncan [4,6]; and WHO [9,22]). An innovative technology for vaccine production is required using the least amount of virus to protect the greatest number of people.

\subsubsection{Other preventive measures}

Today, governments must consider reliable crowd-control measures, enforcement of quarantine, restriction of travel, and use of privately owned buildings for hospitals, and must consider compulsory vaccination to control the spread of the outbreak (Duncan [17]). Individual businesses will need to protect their employees, while working to maintain critical infrastructure services such as power and telecommunications.

In 1918, practitioners rightly assumed that the disease could be spread through the air by coughing or sneezing. Therefore many governments enforced the closure of public places where people might come in close contact with one another. They closed dance halls, libraries, and schools. If people did venture outside, many wore masks. In fact, in some States, it was illegal to go outdoors without a mask, which, incidentally, was useless against flu. Police in many cities had orders to enforce the wearing of masks and to charge offenders.

Since telephones also helped to maintain ties, requests for new lines increased rapidly. But installers, who were at risk of exposure to sick families, wore cheesecloth masks soaked in formaldehyde. If the risk was particularly great, they attached the phone to a board, and pushed it through the window (Duncan [11]).

Should a pandemic occur, telecommuting will be important as both a method of communication, and as a social-distancing measure. A key question must be, 'Will internet, satellite, and telephones, etc. be able to meet the surge in demand over a sustained period of 12-24 months, and a widespread geographic area?'

Telecommunications were disrupted throughout the world on April 8, 2005, the day of the funeral Mass of Pope John Paul II. And the chaos that followed Hurricane Katrina, an event limited in space and time, was magnified by the failure of communications networks; for example, cell phones stopped working when cell towers failed, back-up batteries depleted, and generators ran out of fuel, and satellite and VoIP phones bogged down with uncontrolled traffic.

\subsection{Large numbers of deaths will occur}

The World Health Organization estimates 2 to 7.4 million deaths globally for a pandemic - a conservative estimate based on the mild 1957 influenza pandemic. Estimates based on 1918 are 50 million deaths worldwide (WHO [9]).

Predicting the specific characteristics of a future pandemic virus is difficult. Nobody can predict how pathogenic a new virus will be, and which age groups it will affect; today most cases of $\mathrm{H} 5 \mathrm{~N} 1$ have occurred in previously healthy children and young adults (WHO [3]). Regardless of the numbers of dead, protocols must be developed to prepare for excess mortality and to handle bodies in a safe and respectful manner (Duncan [17]). 
In 1918, upwards of 50 million people succumbed to Spanish flu in a global population of two billion people - and this is a conservative estimate, as it is believed that 25 million may have died in India alone. Many researchers now estimate the number of dead at 100 million. Spanish flu killed more people than the Black Death of the Middle Ages, more people than all the fighting of the First World War, more people than AIDS has to date, and, remarkably, Spanish flu killed in a period of just one year.

Spanish flu killed young healthy people, those in the prime of life: healthy adults, 20-40 years of age. For example, Spanish flu killed Harry Elionsky, America's strongest swimmer, who once swam 90 miles non-stop. Killing the young was particularly tragic because it came on the heels of so many war deaths from the same age group.

As a result of the increased deaths, coffins and undertakers were in short supply. In Rio de Janeiro, one householder pleaded with the fire brigade, conscripted as undertakers, to take his dead brother. They refused, adamant that there was no room on the death cart. The desperate brother continued to plead, as the body was already five days old. The firemen relented; they would take the brother, but in return they would leave a stranger who had died more recently (Duncan [11]).

\subsection{Economic and social disruption will be great}

Today, public health authorities predict that up to $60 \%$ of the work force will be too ill or frightened to leave home and will not attend work. Employee absenteeism could ground planes, and close bars, daycares, and other public places. Global economic activity could weaken, supply chains (including those distributing life-saving drugs) could fail, raw material prices could decrease, risk aversion could intensify, and interest rates could fall; SARS cost the Canadian Public Health System \$945 million, and conservatively cost the economy \$4 billion. On the other hand, health care, home entertainment, internet commerce, and telecommunications companies could benefit (Duncan [4]; International Monetary Fund [23]; The World Bank [24]; UN System Coordinator et al., [25]; and WHO [9]).

In 1918, the losses to business were staggering throughout the world. Merchants suffered because customers were too ill to shop, staff were absent with flu, and transportation was halted. In Montreal, 10,000 railway workers were off the job with flu. Pool halls, restaurants, and theatres all lost heavily, but it was the insurance industry which was perhaps the hardest hit; in London, England, the Prudential Assurance Company paid out two times as much in flu claims as it did in war claims (Duncan $[4,11]$ ).

\section{Responsibility}

Pandemic influenza requires action at all levels - global, national, organizational, and personal. The WHO uses a series of six phases for a pandemic alert system. 
The world is presently in phase three--meaning a new influenza virus subtype is causing disease in humans, but is not yet spreading efficiently among humans (WHO [5, 26]).

Can a pandemic be averted? The answer is unknown. The best way to prevent a pandemic would be to eliminate the influenza virus from birds, but it is unlikely that this could be achieved in the near future, as 200 million birds have been culled worldwide, and the disease continues to spread-most recently to England. Another possibility would be to use antiviral medications to treat early cases, and thus reduce the risk that a fully transmissible virus would emerge. Unfortunately, this strategy has never been tested, and the infection could have passed through three generations before public health officials become aware/recognize the start of a pandemic (WHO [5, 22]).

\subsection{Public and organizational responsibility}

During a pandemic, government will need to protect civil society through measures such as restrictions of mass gatherings, school closures, travel restrictions, voluntary home isolation of cases, and voluntary quarantine (Duncan [17]).

Government must also garner the support of the business community and ask that it be knowledgeable about the risks of pandemic flu, and that it be prepared for the economic and social impacts of a global epidemic (Duncan [4]; and PandemicFlu.gov [18]). Specifically, individual businesses: should develop a pandemic team to liaise with external organizations; should develop an emergency budget; and should develop pandemic scenarios--whether or not a pandemic starts here in North America or overseas, and whether or not a cluster of cases occurs in one's community or organization. And every level of government and business must develop an over-arching strategy - to reduce cases, hospitalizations, and deaths, and economic and social impacts.

In preparing, governments and organizations face legal and ethical challenges that will affect both an individual's chance of survival (e.g. allocation of scarce resources, such as antivirals and vaccines) and freedoms (e.g. travel restrictions). The need for a widely accepted, pre-pandemic ethics approach was highlighted during the 2003 SARS crisis, when difficult ethical choices rapidly arose.

Planning for an influenza pandemic requires compliance with contemporary laws, ethical action, and constructive partnerships among business, communities, and governments to maximize survival and socioeconomic functioning.

\subsubsection{Laws and regulations}

Organizations must ensure that they are in full compliance with global, regional, and local laws and regulations. With regard to health in Canada, for example, most employers and their employees fall under provincial legislation. In Ontario, the Ontario Occupational Health and Safety Act (OHSA) and its Regulations provide the central legislative framework governing workplace safety. 
Because it was not possible to specify all possible workplace hazards, a very broad clause was created in section $25(2)(\mathrm{h})$ of OHSA: 'Without limiting the strict duty imposed by subsection (1), an employer shall, (h) take every precaution reasonable in the circumstances for the protection of a worker.'

Employers therefore have a legal obligation to protect worker health and safety in all situations - and not just those specified. Section 25(2)(h) of OHSA will therefore be important for employers who are reviewing their compliance, particularly regarding non-traditional hazards. According to Peter Brady, McCarthy Tetrault, it is advisable for employers to engage legal and professional experts to determine what constitutes 'every precaution reasonable'.

The law prescribes moral minimums, but ethics may require greater commitments, such as attending to those less powerful (Duncan $[7,8]$ ).

\subsubsection{Ethical considerations}

Addressing ethical issues in pandemic influenza planning is new territory for the WHO. The Ethics Team of the Department of Ethics, Trade, Human Rights and Health Law is currently studying the ethical issues raised by a potential pandemic; a technical meeting was held in May 2006, and the recommendations of the meeting are now being prepared. WHO next expects to provide Member States with practical guidance to incorporate ethical considerations into pandemic plans.

There are currently four working groups: 'equitable access to therapeutic and prophylactic measures; isolation, quarantine, border control, and socialdistancing measures; the role and obligations of healthcare workers during an outbreak of pandemic influenza; and issues that arise between governments when developing a multinational response'. Unfortunately, no working group exists to specifically address ethical concerns of business regarding a pandemic.

Examination of the ethical plans of Canada, the United Kingdom, and the United States of America raises alarm: for example, scarcity of human and material resources is assumed to be severe, yet resources needed to reduce death and other consequences are not identified.

Although ethics is increasingly being addressed (for example, by the Canadian College of Health Service Executives, Center for Infectious Disease Research and Policy, Toronto Academic Health Sciences Network, and the University of Toronto Joint Centre for Bioethics), questions largely focus on healthcare workers, scarce resources, and social-distancing measures. Information can, however, be gleaned from these health reports, which openly discuss moral concerns - in comparison to many companies, such as Boeing or Wal-mart, which were unwilling to share planning details (as of April 30, 2006).

After assuring legal compliance, companies might want to consider the following principles and values in their planning: first, the Precautionary Principle, 'Where an activity raises threats of harm to the environment or human health, precautionary measures should be taken even if some cause and effect relationships are not fully established scientifically.' The Precautionary Principle can be likened to the common sense idea behind many deep-rooted axioms, such as 'better safe than sorry', and 'first do no harm'. Key elements of the Principle 
include taking precaution in the face of scientific uncertainty, and using democratic values to carry out and enforce the Principle.

Second, businesses might want to survey their employees, management, and unions, making sure that the appropriate members of the community are given the opportunity to share their perspectives. Employers need their staff's advice, help, and most important, buy-in. If there is no compliance, even a flawless plan cannot be implemented.

Third, companies might want to determine/re-visit their guiding principles/ethical values so that plans will reflect what most people will accept as fair and good for employee health and organizational health during a possible pandemic. Values might include beneficence, individual liberty, nonmalfeasance, privacy, solidarity, stewardship, and trust. Ethical decision-making should be accountable, inclusive, open and transparent, reasonable, and responsive (as suggested by the University of Toronto Joint Centre for Bioethics).

Adherence to laws, regulations, and ethical principles and values during planning or crisis will allow companies to make difficult decisions regarding: duty to work during a disease outbreak, measures to prevent stigmatization (of those affected or quarantined), priority setting, including the allocation of antivirals, support for those in quarantine, stockpiling of anti-viral drugs, and travel bans (Duncan [8]).

\subsubsection{Business continuity}

Every business also needs a plan to maintain functionality. What is an organization's anticipated demand for goods and services? What are its core activities, key employees, and necessary supplies? What insurance and security measures are necessary?

Consequently, what centralized, coordinated services might be available to organizations, its employees and communities? Have companies undertaken risk analysis and a review of business continuity plans? What delivery, quarantine, trade, and travel restrictions could impact the business?

Business should consider modeling studies regarding the economic impacts of an influenza pandemic based on attack rates and patterns of attack, and should aim to improve projected effects. The Centers for Disease Control and Prevention (CDC) publishes free software on their website (FluAid and FluSurge) (Duncan [4]).

Have corporations developed pandemic-specific continuity procedures? How will companies communicate with government, staff, suppliers, and customers? How will they protect employee health and well being-personal hygiene, protection and workplace cleanliness, social distancing, policies for sick employees and contact management, travel restrictions?

Do corporations know how to recognize a pandemic, and the international, national and regional responsibilities that will come into play? How will companies manage their return to business as usual?

Ignorance regarding pandemic flu is no longer an acceptable defense. Therefore, figure 1 gives a possible pandemic planning guideline for business. 


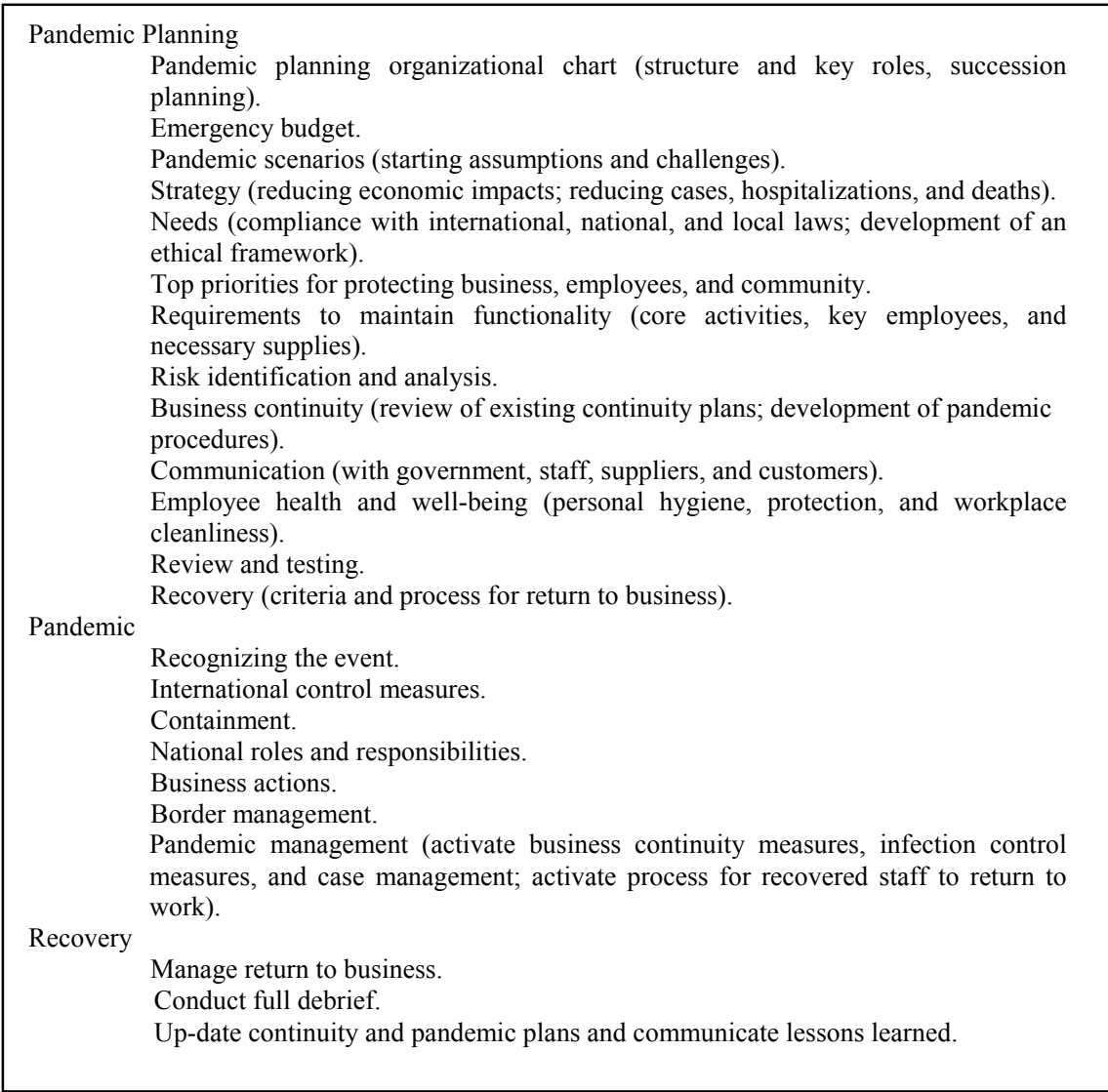

Figure 1: $\quad$ Possible pandemic preparedness guidelines.

\section{Summary}

The second and third decades of the twentieth century experienced two great plagues: Spanish flu, the deadliest disease in recorded history, and encephalitis lethargica. The two claimed the lives of millions worldwide, and both changed families, and the course of history.

History teaches us that we are due for another fatal flu in the future. We must be prepared. The more we know about pandemics, the greater the probability that we will be able to mitigate their deadly effects.

Companies must recognize that choosing the least cost, effort, and time is a choice. They must decide how much information regarding pandemic preparedness to release to civil society and to government, and how to protect employees and the community. Business must recognize the moral distress employees might experience in choosing between family and work, and in making difficult decisions repeatedly over extended periods of time. 
Finally, according to Peter Singer, Director of the University of Toronto Joint Centre for Bioethics (JCB), 'Afterwards, history will judge today's leaders on how well they took decision on the ethical challenges they faced in the midst of the crisis.'

Therefore, each organization must ask how it wants to be judged following a disaster by its employees, shareholders, local communities, and indeed, the global community?

\section{References}

[1] Webby, R., Webster, R. 2003. Are we ready for pandemic influenza? Science 302:1519-22.

[2] Monto, A. 2005. The threat of and an avian influenza pandemic. New England Journal of Medicine 352:323-5.

[3] WHO. 2005 a. Avian influenza frequently asked questions. http://www.who.int/csr/disease/avian_influenza/avian_faqs/en/index.html \#present 31/10/05.

[4] Duncan, K. 2006 a. Business may take a big hit. Toronto Star. http:/www.thestar.com/NASApp/cs/ContentServer?pagename=thestar/La yout/Article_PrintFriendly\&c=Article\&cid $=1138661411815 \&$ call_pageid $=971358637177.02 / 06 / 06$.

[5] WHO. 2007. Cumulative number of confirmed human cases of Avian Influenza A/(H5N1) reported to WHO. http://www.who.int/csr/disease/ avian_influenza/country/cases_table_2007_02_19/en/index.html. 23/02/07.

[6] Duncan, K. 2006 b. Forewarned is forearmed. The 2006 Conference Board of Canada CSR Conference. Toronto, Canada, May 17, 2006.

[7] Duncan, K. 2006 c. Pandemic flu: current threat and call for ethics. Management Ethics. Spring, 2006.

[8] Duncan, K. 2006 d. Ethics Still Un-Addressed In Pandemic Preparedness: Possible Planning Guidelines. Management Ethics, Fall, 2006.

[9] WHO. 2006 a. Ten things you need to know about bird flu. http:/www.who.int/csr/disease/influenza/pandemic10things/en/index.html 30/05/06.

[10] Crosby, 1976. Epidemic and Peace, 1918. Greenwood Press: Westport.

[11] Duncan, K. 2003. Hunting the 1918 Flu: One Scientist's Search for a Killer Virus. University of Toronto Press: Toronto.

[12] Oxford, J., Sefton, A., Jackson, R. et al. 1999. Who's that lady? Nature Medicine 5, 1351 - 1352.

[13] Liu, J., Xiao, H, and Lei, F. et al. 2005. Highly Pathogenic H5N1 Influenza Virus Infection in Migratory Birds. Science, Vol. 309, Issue 5738, 1206.

[14] de Jong, M., Van Cam, B., Qui, P. et al. 2005. Fatal avian influenza A (H5N1) in a child presenting with diarrhea followed by coma. The New England Journal of Medicine Volume 352, Number 7:686-691. 
[15] Taubenberger, J., Reid, A., Lourens, R. et al. 2005. Characterization of the 1918 influenza virus polymerase genes. Nature 437: 889-893.

[16] Toner, E., Waldhorn, R., Maldin, B. et al. 2006. Meeting report. Hospital preparedness for pandemic influenza. Biosecurity and Bioterrorism: Biodefense, Strategy, and Practice 4 (2).

[17] Duncan, K. 2005. Lesson from the 'Spanish Lady'. University of Toronto Bulletin November 8, 2005.

[18] PandemicFlu.gov. 2006 a. Business and industry planning. http://www. pandemicflu.gov/plan/tab4.html. 02/06/06.

[19] CTV. 2006. Canada stockpiling antivirals in case of pandemic. http://avianflu. futurehs.com/?cat=5. 02/06/06.

[20] PandemicFlu.gov. 2006 b. Community planning. http://www. pandemicflu.gov/plan/tab7.html. 02/06/06.

[21] PandemicFlu.gov. 2006 c. Individual and family planning. http://www. pandemicflu.gov/plan/tab3.html. 02/06/06.

[22] WHO. 2006 b. Avian influenza ('bird flu) - Fact sheet. http://www. who.int/mediacentre/factsheets/avian_influenza/en/index.html30/05/06.

[23] International Monetary Fund. 2006. The global and economic impact of an avian flu pandemic and the role of IMF. http://www.imf.org/ external/pubs/ft/afp/2006/eng/022806.pdf. 02/06/06.

[24] The World Bank. 2006. Economic impact of avian flu. http:/web.worldbank.org/WBSITE/EXTERNAL/COUNTRIES/EASTAS IAPACIFICEXT/EXTEAPREGTOPHEANUT/0,,contentMDK:20713527 $\sim$ pagePK:34004173 piPK:34003707 theSitePK:503048,00.html. 02/06/06.

[25] Un System Coordinator and World Bank. 2006. Responses to avian and human influenza threats; progress, analysis, and recommendations January-June 2006. http://siteresources.worldbank.org/INTTOPAVIFLU/ Resources/UNSIC_Report_Vienna_Final.pdf. 02/06/06.

[26] WHO. 2005 b. Current WHO phase of pandemic alert. http:// www.who.int/csr/disease/avian_influenza/phase/en/index.html. 30/05/06. 